\title{
Effect of Designed Teaching Protocol Regarding Patients' Safety after Cardiac Catheterization on Nurses' Performance and Patients' Incidence of Vascular Complications
}

\author{
Heba Abd Elkader Ali ${ }^{1} \&$ Marwa Mosaad $\mathrm{Ali}^{1}$ \\ ${ }^{1}$ Medical-Surgical Nursing, Benha University, Egypt \\ Correspondence: Heba Abd Elkader, Lecturer, Medical-Surgical Nursing, Benha University, Egypt.
}

Received: February 5, 2019

Accepted: March 14, 2019

Online Published: March 21, 2019

doi:10.20849/ijsn.v4i1.555

URL: https://doi.org/10.20849/ijsn.v4i1.555

\begin{abstract}
Background: Vascular access-site complications are an important cause of morbidity and mortality, which is related mainly to vascular percutaneous intervention procedures and requires safe and standardized care policies, as well as qualified and skilled health provider to obtain good outcome of management. Aim of the study: to investigate the effect of designed teaching protocol regarding patients' safety after cardiac catheterization on nurses' performance and patients' incidence of vascular complications. Aquasi-experimental design was used to conduct the current study in cardiac catheterization and coronary care units at Benha University Hospital during the period from beginning of April 2018 till beginning of October 2018. Subjects: A sample of convenience of 50 nurses who are willing to participate in the study, and patients who admitted for performing cardiac catheterization were 170 patients recruited according to the study formula based on the total number admitted to the study settings during 2017. Tools: Two tools were utilized for data collection, (I) Structured interviewing questionnaire for nurses, (II) Patients' assessment sheet. Results: Showed that nurses' level of knowledge and practice post implementing the designed teaching protocol was higher than pre implementation, with a significant correlation between nurses' knowledge and practice $\left(\mathrm{p}=<0.001^{* *}\right)$, besides a lower incidence of complications among patients in intervention group than in control group . Conclusion: The designed teaching protocol was effective in improving nurses' knowledge and practice, which were positively associated with each other and lower incidence of vascular complications among patients in the intervention group. Recommendation: The study suggested equipping cardiac catheterization unit with simple illustrated guidelines protocol covering percutaneous coronary intervention procedure practices knowledge pre/post cardiac catheterization.
\end{abstract}

Keywords: cardiac catheterization, designed teaching protocol, patients' safety, nurses' performance, vascular complications

\section{Introduction}

\subsection{Cardiac Catheterization}

Cardiac catheterization is a process that is supposed as the golden standard for diagnosing, evaluating, and treating cardiac diseases. One or more catheters are inserted through a peripheral blood vessel in either the antecubital artery or vein or femoral artery or vein with x-ray guidance (Arathy, 2011). The purpose of this procedure is for diagnostic or interventional reasons. Regarding diagnostic cardiac catheters, are inserted so that blood flow and pressure in the chambers of the heart can be evaluated; while interventional cardiac catheters are preferred as an alternative to open heart surgery (Santos and Ward, 2017).

Major advances in percutaneous coronary intervention (PCI) have included increasingly complex antiplatelet and antithrombotic regimens used in conjunction with PCI. Unfortunately, although these advances yield benefits, they also contribute to many risks associated with femoral sheath removal, the most common type of these complications is the vascular type, especially associated with inadequate hemostasis which exposes patients to additional discomfort, extended hospital stays, higher hospital costs, and reduces the patients' outcomes, painful haematoma , ecchymosis, and oozing are the most common signs, also development of pseudo-aneurysm, arteriovenous fistulas, thrombosis, thromboemboli, and retroperitoneal bleed (Ebeed et al., 2017).

Vascular complications arise from compression of the femoral vasculature, and its incidence is close to $1 \%$ for diagnostic cardiac catheterization and 3\% for PCI (Parkinson, 2015), which widely varies after sheath removal 
following PCI procedure according of the compression method used to achieve femoral artery hemostasis (Hamel, 2012). Hematoma, ecchymosis and oozing are considered minor complications post percutaneous coronary intervention. Hematoma is a collection of blood located in the soft tissue and is identified by local swelling, hardness, and pain. As well as it considered the most common vascular access site complication. Management of hematoma requires pressure to the groin, bed rest, and careful monitoring. Ecchymosis is a common complication, with presence of skin discoloration and is accompanied by pain and minor swelling. During the first twenty-four hours after the procedure, a warm compress may be applied to the site to ease discomfort. Oozing can be resolved through continued manual pressure until the oozing subside (Panizza et al., 2017).

Major predictors of such complications following coronary interventional procedures include advanced age, repeat percutaneous transluminal coronary angioplasty, female gender, and peripheral vascular disease. Minor predictors include level of anticoagulation, use of thrombolytic agents, elevated creatinine levels, low platelet counts, longer periods of anticoagulation, and use of increased sheath size (Ahmed, 2015).

Many patients suffer from preventable harm during health care in hospitals (Panesar et al., 2016). Improving patient safety is at the forefront of policy and practice and is defined as being free from accidental harm as a result of a health care encounter removing femoral sheaths and managing related complications after PCI, such as promoting hemostasis as an essential issue are predominantly the responsibilities of nurses in many acute and critical care settings (Chen \& Crozier, 2014).

Therefore, nurses are playing an important role in post cardiac catheterization patients' management, and cardiac catheterization staff and nurses should be work together to reduce complications, when possible, and treat these complications when they occur. Careful nurses' assessment and monitoring are required in order to achieve these goals. Besides, nurses with specialized in cardiac training must need to assess, identify and manage the blood vessels (Feroze et al., 2017).

\subsection{Significance of the Study}

While coronary artery disease is the leading cause of morbidity and mortality in both men and women, cardiac interventions are widely accepted as a practical management option and with the increasing number of cardiac catheterizations performed, as well as evolving technology, an inadequate hemostasis leads to vascular complications which relate to patients safety and illness, arising from health care provider and organization system factor, due to the differences in the knowledge and practices of the nurses in the clinical setting. Awareness and skillfulness regarding patient safety have an influence on risk to patient safety (Ahmed, 2015). So, there was a need to assess the existing knowledge and practices in order to provide the informational manual based on the findings obtained which would help the nurses to bring their knowledge into practice thereby preventing the client from post cardiac catheterization complications

\subsection{Aim of the Study}

The aim of the present study was to investigate the effect of designed teaching protocol regarding patients' safety after cardiac catheterization on nurses' performance and patients' incidence of vascular complications. Through,

- Assessing nurses' knowledge regarding patients' safety after cardiac catheterization

- Assessing nurses' practice regarding patients' safety after cardiac catheterization

- Implementing designed teaching protocol regarding patients' safety after cardiac catheterization

- Evaluating the effect of designed teaching protocol on nurses' knowledge, and practice as well as patients' incidence of vascular complications

\subsection{Research Hypotheses}

To fulfill the aim of this study the following research hypotheses were formulated:

H1: The level of nurses' knowledge post protocol implementation will be higher than knowledge level before implementation.

H2: The level of nurses' practice post protocol implementation will be higher than practice level before implementation.

H3: A significant correlation will exist between knowledge and practice scores obtained by nurses receiving a designed teaching protocol.

H4: The incidence of vascular complications among patients who cared for by nurses post designed teaching protocol implementation (intervention group) will be lower than those who cared for by nurses pre-designed teaching protocol implementation (control group). 


\section{Subjects and Methods}

\subsection{Research Design}

Quasi-experimental design was utilized to conduct the current study.

\subsection{Setting}

This study was conducted in cardiac catheterization and coronary care units at Benha University Hospital.

\subsection{Subjects}

2.3.1 Convenient sample of 50 nurses who are willing to participate in the study, and patients who admitted for performing cardiac catheterization were 170 .

2.3.2 Size: The sample size of patients was calculated based on the previous year census report of admission in cardiac catheterization unit from Benha University Hospital Census, 2017. Utilizing the following formula (Yamane, 1967).

$$
\mathrm{n}=\frac{\mathrm{N}}{1+\mathrm{N}(\mathrm{e})^{2}}
$$

Where:

$\mathrm{n}=$ sample size

$\mathrm{N}=$ total population $(306)$

$\mathrm{e}=$ margin error $(0.05)$

Patients were randomly assigned into two equally homogeneous groups (control group) patients who cared for by nurses prior to designed teaching protocol implementation and (intervention group) patients who cared for by nurses post designed teaching protocol implementation ( $85 \& 85$, respectively) Matching was done according to age, education, gender, co morbidity diseases (diabetes\& hypertension) and diagnosis, according to the following criteria: Age 18 years or older, both sexes (male and female), able to communicate, and accept to participate in the study as well as having normal Prothrombin Time (PT) and Partial Thromboplastin Time (PTT). With successful single wall puncture of the femoral artery for (PCI) were included. Exclusion criteria: Had peripheral vascular diseases, hemodynamically unstable e.g., bleeding disorders and patients receiving mechanical ventilation, or thrombolytic therapy within 24 hours before or during the Percutaneous Coronary Intervention Procedure (PCIP). Also patients with previous surgery in the iliac or femoral arteries.

\subsection{Tools of Data Collection}

\section{Two tools were utilized for data collection.}

\subsubsection{Tool (I)}

Structured interviewing questionnaire for nurses (pre/ post test)

\section{Covers the following parts}

Part 1: Concerned with socio-demographic characteristics of nurses including; age, gender, marital status, qualification, years of experience,... etc.

Part 2: Knowledge questionnaire: for assessing nurses' knowledge about patients' safety after cardiac catheterization, it contains 10 questions regarding several aspects of preventing complications after cardiac catheterization, after care, blood investigations, physical activity etc . it was developed by (Arathy, 2011).

Scoring system: The total score for all items was. For the knowledge items, a correct response was scored 1 and the incorrect zero. The total nurse's knowledge was considered satisfactory if the percent score was $70 \%$ or more and unsatisfactory if less than $70 \%$.

Part 3: Structured practice questionnaire (pre/post test): This scale aimed at assessment of actual nurses' practice regarding patients' safety protocol in order to prevent vascular complications consisted of 18 items; it was developed by (Feroze et al., 2017)

Scoring system: The total score for all items of the practice observed to be done always were scored (2), done sometimes scored (1) and the items not done were scored (0). The total practice was considered adequate if the percent score was $80 \%$ or more and inadequate if less than $80 \%$. 


\subsubsection{Tool (II)}

Patients' assessment sheet: It was divided into the following parts:

Part (1): Related to socio-demographic characteristics of patients (e.g., age, sex, marital status, level of education, and occupation, BMI, and comorbidity ,...etc.

Part (2): Medical data sheet involve: including femoral sheath size, time sheath indwelling. Blood pressure post line removal, post procedure heparin, and length of hospital stay, etc.......

\section{Part (3): Vascular complications scale: It includes}

- Hematoma Formation Scale: The scale was designed for measurement of hematoma size, adopted from Al Sadi et al. (2010). Classified hematoma according to surface area as: No hematoma $\left(<2 \mathrm{~cm}^{2}\right.$ in diameter), small hematoma $\left(2 \leq 5 \mathrm{~cm}^{2}\right.$ in diameter), medium hematoma $\left(5 \leq 10 \mathrm{~cm}^{2}\right.$ in diameter) and large hematoma $(\geq$ $10 \mathrm{~cm}^{2}$ in diameter).

- Ecchymosis Scale: It was designed for measurement of ecchymosis size, adopted from Hamner et al. (2010). Classified ecchymosis into four categories according to surface area as: No ecchymosis $\left(<2 \mathrm{~cm}^{2}\right.$ in diameter), small ecchymosis $\left(2 \leq 5 \mathrm{~cm}^{2}\right.$ in diameter), medium ecchymosis $\left(5 \leq 10 \mathrm{~cm}^{2}\right.$ in diameter) and large ecchymosis $\left(\geq 10 \mathrm{~cm}^{2}\right.$ in diameter).

-Oozing Scale: The scale was designed for measurement any leakage of blood from the puncture site, was adopted from Black (2008), and classified oozing according to surface area soaked with blood as: No oozing (dry dressing), mild oozing $\left(<2 \mathrm{~cm}^{2}\right.$ in diameter dressing soaked with blood), moderate oozing $\left(2 \leq 5 \mathrm{~cm}^{2}\right.$ in diameter dressing soaked with blood) and severe oozing $\left(5 \leq 10 \mathrm{~cm}^{2}\right.$ in diameter dressing soaked with blood). For hematoma formation, ecchymosis and oozing scales, it was filled by the researchers immediately, at 6 and at 12 hours post hemostasis.

\subsubsection{A Designed Teaching Protocol about Nurses' Role Regarding Patients' Safety after Cardiac Catheterization}

It was developed by researchers based on nurses and patients need assessment, literature review, researchers' experience and opinions of the medical and nursing expertise; it was written in Arabic using simple language with illustrations.

\section{Tool validity}

The content validity was done through 7 panels of expertise in medical and nursing specialty for face and content validity, and their opinions were requested via an assessment form. The experts were asked to grade each item as "essential," "useful but inadequate" or "unnecessary". Modification was carried out according to the panel's judgment on the clarity of sentences and appropriateness of content. The percentage of consensus among experts regarding structured interviewing questionnaire was $97 \%$, observational checklist was $98 \%$ and Vascular complications scale was $99 \%$.

\subsection{Pilot Study}

It was conducted on $10 \%$ of the total sample (nurses \& patients), and they were excluded from the study sample. In order to determine time required to complete data collection, test the feasibility and reliability of tools. Regarding cronbach alpha values for knowledge questionnaire sheet, structured practice questionnaire as well as vascular complications scale were as follows: $0.91,0.94$, and 0.98 , respectively.

\subsection{Ethical Considerations}

This study was conducted after primary approval was obtained from Ethics Committee, faculty of nursing, Benha University. Then an official permission was obtained from the director of coronary care unit in benha university hospital. An explanation about the purpose of the study was given to participants, and they were also informed that they could withdraw from the study at any time before the completion of the study. After agreement for Participation in the study, participants were asked to sign a consent form. Moreover, they were reassured that all information gathered would be confidential and used only for the purpose of the study.

\subsection{Field of Work}

\section{Data were collected in the following sequence}

2.7.1 Once official permission to carry out the study was obtained from pertinent authorities after explanation of its purpose. Structured interview was conducted individually for patients eligible for the study (fulfilled the inclusion and exclusion criteria) in order to explain the purpose of the study, assure confidentiality and to obtain informed written consent. 
- Data collection extended over a period of six months from beginning of April 2018 till the beginning of October 2018.

\subsubsection{Procedures}

The designed teaching program comprised the following phases:

\section{A- Assessment Phase:}

Each cardiac nurse was interviewed individually before applying the designed protocol in order to identify the baseline nurse's knowledge and practice of patient's safety after cardiac catheterization using tool 1 . This interview took about 20 to 25 minutes, also patients assigned to control group were interviewed individually in order to collect their sociodemographic and clinical data as well as to detect incidence of vascular complications at immediate, after $6 \mathrm{hrs}$ and 12 hours of hemostasis using tool 2.

B- Planning phase: Developing teaching protocol by the researcher was done according to nurses' assessment moreover, teaching materials included (discussion, demonstration, and booklet).

\section{C- Implementation phase}

The designed teaching protocol was implemented for nurses in the mentioned setting. Patients were divided equally to either control group or intervention group ( 85 patients in each group). Selecting the patient was done according to the allocated assessment times before and after a designed teaching protocol.

It was conducted in 3 sessions, at morning, and after noon shifts. The first session was carried out during assessment phase, involved (overview about heart and coronary arteries, coronary artery disease and cardiac catheterization) and the second session involved (nursing management for patient undergoing cardiac catheterization) while the third involved (predischarge instructions which should be taught to patients). The researcher scheduled with them the teaching sessions and the nurses were divided into small groups, each group contains 3-4 nurses. Teaching has been implemented for nurses in terms of sessions and teaching on the spot during their official working hours. The duration of each session was about 35-40 minutes, including 10 minutes for discussion.

Designed teaching protocol: It was developed by the researcher from literature reviews, researcher experience and opinions of the medical and nursing expertise based on patient's assessment needs to maintain health promotion for patients. The teaching booklet was revised and modified based on the expertise comments, it was written in Arabic using simple language with illustrations and it was concerning knowledge about:

1. Brief illustration of the anatomy and physiology of the heart and coronary arteries.

2. Information about coronary artery disease (definition, causes, symptoms, and nursing care)

3. Information about cardiac catheterization (what's it, function, indications, types, complications... etc.)

4. Nursing management for patients undergoing (pre, during and after) cardiac catheterization, especially regarding vascular complications

5. Discharge instructions which should be given for patients

\section{D- Evaluation phase}

Immediately after implementation of the designed teaching protocol, nurse's knowledge and practice were evaluated by the researcher through filling the study tools I, parts $(2,3)$, also vascular complications was evaluated for patients in intervention group at immediate, after 6 hrs and 12 hours of hemostasis using tool II.

\subsection{Data Analysis}

The collected data were tabulated and statistically analyzed using an IBM computer and the statistical package for social science (SPSS) advanced statistics, version 20 (SPSS Inc., Chicago, IL). Numerical data were expressed as mean and standard deviation. Qualitative data were expressed as frequency and percentage. Chi-square test was used to examine the relation between qualitative variables. For quantitative data, comparison between two groups was done using student t-test. Pearson method was used to test correlation between numerical variables. A p-value $<0.05$ was considered significant, and $<0.001$ was considered highly significant.

\section{Results}

Table 1. Presents sociodemographic characteristics of nurses under the study, it was observed that, the mean age of them was $(30.60 \pm 7.96)$ years. It also shows that $(82.0 \%)$ were female and $(76.0 \%)$ were married, with $(52.0 \%)$ had general diploma, and (76.0\%) of them didn't attend in-service educational program, moreover, nurses' mean years of experience in cardiac unit was $(4.76 \pm 4.09)$, while that of general experience in hospital setting was $(6.38 \pm 5.84)$

Table 2. Shows a significant difference between nurses' knowledge during pre and post program, indicating $(86.0 \%)$ of them had unsatisfactory level preprogram to reach at a satisfactory level among $(82.0 \%)$ of them during post program 
Table 3. Reveals a significant difference between nurses' practice during pre and post program, indicating that all $(100.0 \%)$ of them had in adequate level of practice preprogram, while (58.0\%) of them had a adequate level of practice during post program

Table 4. Shows that, there is a positive and significant correlation between nurses' knowledge and practice after implementing program.

Table 5. Points out that there is no significant difference between both (control \&intervention groups) regarding their sociodemographic characteristics, with a mean age of $(54.60 \pm 4.78 \& 54.31 \pm 4.94$, respectively) and more than half $(55.6 \% \& 56.2 \%$, respectively) of both groups were male as well as, $(52.3 \% \& 57.9 \%$, respectively) were married, more over their mean body mass index was $(28.83 \pm 1.46 \& 29.10 \pm 1.00$, respectively).

Table 6. Clarifies that there is no significant difference between both (control \& intervention groups) regarding their clinical data, with a round three quadrants $(77.6 \% \& 71.8 \%$, respectively) had co morbid diseases and more than half $(55.6 \% \& 56.2 \%$, respectively) of both groups were male as well as, $(63.5 \%$ \& $49.4 \%$, respectively) their used femoral sheath size was 7 FR

Table 7-a. This table reveals that, there was no significant difference between both groups regarding incidence of hematoma immediately after sheath removal, while there was a significant difference after (6 hrs and $12 \mathrm{hrs})$ of removal $\left(p=0.003^{*} \&<0.001^{* *}\right.$, respectively). Reflecting that the higher percent $(45.9 \%$ and $41.2 \%$, respectively) of intervention group during these periods had no hematoma.

Table 7-b. Clarifies that, there was no significant difference between both groups regarding incidence of ecchymosis immediately after sheath removal, while there was a significant difference after ( $6 \mathrm{hrs}$ and $12 \mathrm{hrs})$ of removal $\left(\mathrm{p}=<0.001^{* *} \&<0.001^{* *}\right.$, respectively). Reflecting that the higher percent $(62.4 \%$ and $50.6 \%$, respectively) of intervention group during these periods had no ecchymosis.

Table 7-c. This table reveals that, there was no significant difference between both groups regarding incidence of oozing immediately after sheath removal, while there was a significant difference after (6 hrs and $12 \mathrm{hrs}$ ) of removal ( $\mathrm{p}=0.007^{* *} \& 0.005^{*}$, respectively). Reflecting that the higher percent $(51.8 \%)$ of intervention group had small oozing after $6 \mathrm{hrs}$ and $(55.3 \%)$ of them had no oozing after $12 \mathrm{hrs}$ of sheath removal.

Table 1. Distribution of the studied nurses according to their socio-demographic characteristics $(n=50)$

\begin{tabular}{|c|c|c|}
\hline \multirow{2}{*}{\multicolumn{3}{|c|}{ Socio-demographic characteristics }} \\
\hline & & \\
\hline$<30$ & 26 & 52.0 \\
\hline $30-<40$ & 14 & 28.0 \\
\hline $40 \geq$ & 10 & 20.0 \\
\hline Mean \pm SD & \multicolumn{2}{|c|}{$30.60 \pm 7.96$} \\
\hline Gender & & \\
\hline Male & 9 & 18.0 \\
\hline Female & 41 & 82.0 \\
\hline \multicolumn{3}{|l|}{ Marital status } \\
\hline Not married & 12 & 24.0 \\
\hline Married & 38 & 76.0 \\
\hline \multicolumn{3}{|l|}{ Qualification } \\
\hline General diploma & 26 & 52.0 \\
\hline $\mathrm{BSc}$ & 24 & 48.0 \\
\hline \multicolumn{3}{|l|}{ In service education program } \\
\hline No & 38 & 76.0 \\
\hline Yes & 12 & 24.0 \\
\hline \multicolumn{3}{|l|}{ Years of experience in cardiac unit } \\
\hline$<1$ year & 20 & 40.0 \\
\hline $1-<5$ years & 3 & 6.0 \\
\hline $5-<10$ years & 17 & 34.0 \\
\hline 10 years $\geq$ & 10 & 20.0 \\
\hline Mean $\pm \overline{\text { SD }}$ & \multicolumn{2}{|c|}{$4.76 \pm 4.09$} \\
\hline \multicolumn{3}{|l|}{ General years of experience in hospital setting } \\
\hline $1-<5$ years & 20 & 40.0 \\
\hline $5-<10$ years & 12 & 24.0 \\
\hline 10 years $\geq$ & 18 & 36.0 \\
\hline Mean \pm SD & \multicolumn{2}{|c|}{$6.38+5.84$} \\
\hline
\end{tabular}

(BSc) Baccalaureate 
Table 2. Difference between nurses' knowledge before and after implementing the program $(n=50)$

\begin{tabular}{|c|c|c|c|c|c|}
\hline \multirow[t]{2}{*}{ Total knowledge } & \multicolumn{2}{|c|}{$\begin{array}{c}\text { Knowledge } \\
\text { (pre program) }\end{array}$} & \multicolumn{2}{|c|}{$\begin{array}{c}\text { Knowledge } \\
\text { (post program) }\end{array}$} & \multirow[t]{2}{*}{$\begin{array}{c}\text { chi square } \\
\text { p- value }\end{array}$} \\
\hline & (No.) & $\%$ & (No.) & $\%$ & \\
\hline Un satisfactory & 43 & 86.0 & 9 & 18.0 & 95.869 \\
\hline Satisfactory & 7 & 14.0 & 41 & 82.0 & $<0.001 * *$ \\
\hline
\end{tabular}

$* *$ Highly statistically significant at $\leq 0.01$

Table 3. Difference between nurses' practice before and after implementing the program $(n=50)$

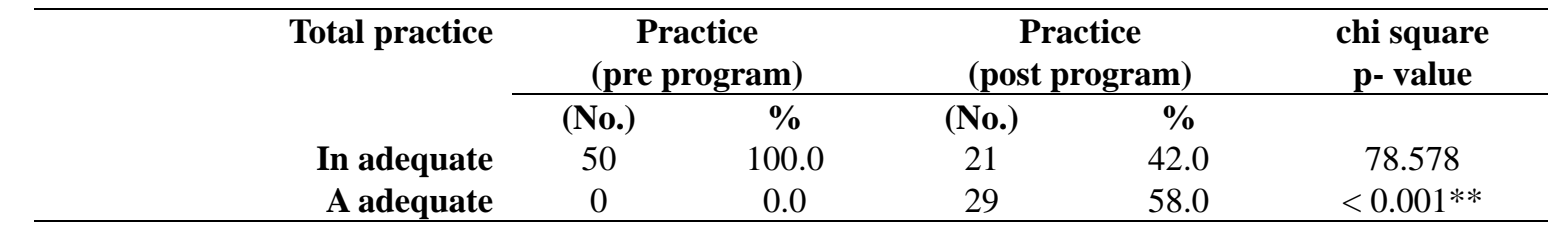

$* *$ = Highly statistically significant at $\leq 0.01$

Table 4. Correlation between total knowledge and practice among nurses after implementing program $(n=50)$

\begin{tabular}{lccc}
\hline Variable $\mathrm{r}-\backslash \mathrm{p}$ values & Total practice & \\
\hline Total knowledge & r-test & $\boldsymbol{P}$-value \\
\hline
\end{tabular}

** $=$ Highly statistically significant at $\leq 0.01$

Weak $=$ indicates $(r<0.5) \quad$ Good $=$ indicates $(r>0.5-0.75)$

Fair $=$ indicates $(r=0.5) \quad$ Very good $=$ indicates $(r>0.75)$

Table 5. Distribution of both studied groups according to their characteristics, control group ( $\mathrm{n}=85)$ and intervention group $(n=85)$

\begin{tabular}{|c|c|c|c|c|c|}
\hline \multirow{2}{*}{$\begin{array}{l}\text { Sociodemographic } \\
\text { characteristics }\end{array}$} & \multicolumn{2}{|c|}{ Control group $(n=85)$} & \multicolumn{2}{|c|}{ Intervention group $(n=85)$} & \multirow{2}{*}{$\begin{array}{l}\text { chi square } \\
\text { p- value }\end{array}$} \\
\hline & (No.) & $\%$ & (No.) & $\%$ & \\
\hline \multicolumn{6}{|l|}{ Age } \\
\hline$<50$ years & 5 & 5.9 & 5 & 5.9 & 4.614 \\
\hline $50-<60$ years & 62 & 72.9 & 60 & 70.6 & $1.000^{\text {n.s }}$ \\
\hline$\geq 60$ & 18 & 21.2 & 20 & 23.5 & \\
\hline Mean \pm SD & \multicolumn{2}{|c|}{$54.60 \pm 4.78$} & \multicolumn{2}{|c|}{$54.31 \pm 4.94$} & $\begin{aligned} \mathrm{t} \text { test } & =0.395 \\
\mathrm{p} \text { value } & =0.694^{\mathrm{n}}\end{aligned}$ \\
\hline \multicolumn{6}{|l|}{ Gender } \\
\hline Male & 50 & 55.6 & 45 & 56.2 & 2.361 \\
\hline Female & 35 & 43.8 & 40 & 44.4 & $0.124^{\text {n.s }}$ \\
\hline \multicolumn{6}{|l|}{ Marital status } \\
\hline Not married & 16 & 42.1 & 22 & 47.7 & 1.220 \\
\hline Married & 69 & 52.3 & 63 & 57.9 & $0.269^{\text {n.s }}$ \\
\hline \multicolumn{6}{|l|}{ BMI } \\
\hline $18.5-<25 \mathrm{k} / \mathrm{m}^{2}$ & 1 & 1.2 & 0 & 0.0 & 1.119 \\
\hline $20-<30 \mathrm{k} / \mathrm{m}^{2}$ & 67 & 78.8 & 66 & 77.6 & $0.572^{n . s}$ \\
\hline$\geq 30 \mathrm{k} / \mathrm{m}^{2}$ & 17 & 20.0 & 19 & 22.4 & \\
\hline Mean \pm SD & \multicolumn{2}{|c|}{$28.83 \pm 1.46$} & \multicolumn{2}{|c|}{$29.10 \pm 1.00$} & $\begin{array}{c}\mathrm{t} \text { test }=-1.408 \\
\mathrm{p} \text { value }=0.161^{\mathrm{n}}\end{array}$ \\
\hline
\end{tabular}


Table 6. Distribution of both studied groups according to their clinical data (control group $n=85$, and intervention group $\mathrm{n}=85$ )

\begin{tabular}{|c|c|c|c|}
\hline \multirow[t]{2}{*}{ Clinical data } & Control group $(\mathrm{n}=85)$ & Intervention group $(n=85)$ & \multirow{2}{*}{$\begin{array}{c}\text { chi square } \\
\text { p- value }\end{array}$} \\
\hline & (No.) $\%$ & (No.) $\%$ & \\
\hline \multicolumn{4}{|l|}{$\begin{array}{l}\text { Presence of co-morbid } \\
\text { disease }\end{array}$} \\
\hline No & 22.4 & 28.2 & 0.778 \\
\hline Yes & 77.6 & 71.8 & $0.378^{\mathrm{n} . \mathrm{s}}$ \\
\hline \multicolumn{4}{|l|}{ Femoral sheath size (FR) } \\
\hline 6 & 31.8 & 43.5 & 3.463 \\
\hline 7 & 63.5 & 49.4 & $0.177^{\mathrm{n} . \mathrm{s}}$ \\
\hline 8 & 4.7 & 7.1 & \\
\hline \multicolumn{2}{|l|}{ Mean \pm SD } & & $\begin{array}{l}\text { T- test } \\
\text { p-value }\end{array}$ \\
\hline Sheath time indwelling & $19.12 \pm 1.92$ & $18.53 \pm 2.29$ & $\begin{array}{c}1.815 \\
0.071^{\text {n.s }}\end{array}$ \\
\hline Time pressure held & $18.00 \pm 2.46$ & $17.52 \pm 2.51$ & $\begin{array}{c}1.232 \\
0.220^{\text {n.s }}\end{array}$ \\
\hline $\begin{array}{l}\text { Blood pressure post line } \\
\text { removal }\end{array}$ & $137.88 \pm 7.33$ & $138.70 \pm 6.68$ & $\begin{array}{c}-0.824 \\
0.411^{\text {n.s }}\end{array}$ \\
\hline $\begin{array}{l}\text { Pre procedure heparin } \\
\text { dose }\end{array}$ & $3129.41 \pm 2178.29$ & $3023.52 \pm 2242.58$ & $\begin{array}{c}0.312 \\
0.755^{\text {n.s }}\end{array}$ \\
\hline $\begin{array}{l}\text { heparin dose during } \\
\text { procedure }\end{array}$ & $700.00 \pm 246.40$ & $647.00 \pm 229.17$ & $\begin{array}{c}1.450 \\
0.149^{\text {n.s }}\end{array}$ \\
\hline
\end{tabular}

(n.s) Not Significant

Table 7-a. Difference between both (control \& intervention) groups according to incidence of vascular complications (hematoma) after sheath removal (control group $n=85$, and intervention group $n=85$ )

\begin{tabular}{lccccc}
\hline Clinical data & $\begin{array}{c}\text { Control group (n=85) } \\
\text { (No.) }\end{array}$ & $\mathbf{\%}$ & $\begin{array}{c}\text { Intervention group (n=85) } \\
\text { (No.) }\end{array}$ & $\begin{array}{c}\text { chi square } \\
\text { p- value }\end{array}$ \\
\hline Hematoma (immediate) & & & & & \\
No hematoma & 46 & 54.1 & 58 & 68.2 & 4.518 \\
Small hematoma & 28 & 23.9 & 21 & 24.7 & $0.211^{\text {n.s }}$ \\
Medium hematoma & 7 & 8.2 & 5 & 5.9 & \\
Large hematoma & 4 & 4.7 & 1 & 1.2 & \\
Hematoma (after 6 hours) & & & & & \\
No hematoma & 20 & 23.5 & 39 & 45.9 & 13.615 \\
Small hematoma & 37 & 43.5 & 28 & 32.9 & $0.003^{*}$ \\
Medium hematoma & 15 & 17.6 & 15 & 17.6 & \\
Large hematoma & 13 & 15.3 & 3 & 3.5 & \\
Hematoma (after 12 hours) & & & & & \\
No hematoma & 13 & 15.3 & 35 & 41.2 & 16.133 \\
Small hematoma & 26 & 30.6 & 24 & 28.2 & $<0.001^{* *}$ \\
Medium hematoma & 32 & 37.6 & 20 & 23.5 & \\
Large hematoma & 14 & 16.5 & 6 & 7.1 & \\
\hline
\end{tabular}

(n.s) Not Significant $(*)$ Statistically Significant at $\leq 0.05(* *)$ Highly statistically significant at $\leq 0.01$ 
Table 7-b. Difference between both (control \& intervention) groups according to incidence of vascular complications (ecchymosis) after sheath removal (control group $n=85$, and intervention group $n=85$ )

\begin{tabular}{lccccc}
\hline \multicolumn{1}{c}{ Clinical data } & \multicolumn{2}{c}{ Control group (n=85) } & $\begin{array}{c}\text { Intervention group } \\
(\mathbf{n = 8 5})\end{array}$ & $\begin{array}{c}\text { chi square } \\
\text { p- value }\end{array}$ \\
& (No.) & $\mathbf{\%}$ & $\mathbf{( N o . )}$ & $\mathbf{\%}$ & \\
\hline \multicolumn{1}{c}{ Ecchymosis (immediate) } & & & & & \\
No Ecchymosis & 66 & 77.6 & 75 & 88.2 & 3.374 \\
Small Ecchymosis & 13 & 15.3 & 7 & 8.2 & $0.185^{\text {n.s }}$ \\
Medium Ecchymosis & 6 & 7.1 & 3 & 3.5 & \\
Large Ecchymosis & 0 & 0.0 & 0 & 0.0 & \\
Ecchymosis (after 6 hours) & & & & & \\
No Ecchymosis & 27 & 31.8 & 53 & 62.4 & 22.862 \\
Small Ecchymosis & 19 & 22.4 & 19 & 22.4 & $<0.001^{* *}$ \\
Medium Ecchymosis & 29 & 34.1 & 12 & 14.1 & \\
Large Ecchymosis & 10 & 11.8 & 1 & 1.2 & \\
Ecchymosis (after 12 hours) & & & & & \\
No Ecchymosis & 24 & 28.2 & 43 & 50.6 & 20.459 \\
Small Ecchymosis & 22 & 25.9 & 24 & 28.2 & \\
Medium Ecchymosis & 19 & 22.4 & 16 & 18.8 & \\
Large Ecchymosis & 20 & 23.5 & 2 & 2.4 & \\
\hline
\end{tabular}

(n.s) Not Significant $* *=$ Highly statistically significant at $\leq 0.01$

Table 7-c. Difference between both (control \& intervention) groups according to incidence of vascular complications (oozing) after sheath removal (control group $n=85$, and intervention group $n=85$ ).

\begin{tabular}{|c|c|c|c|c|c|}
\hline \multirow[t]{2}{*}{ Clinical data } & \multicolumn{2}{|c|}{ Control group $(\mathrm{n}=\mathbf{8 5})$} & \multicolumn{2}{|c|}{$\begin{array}{l}\text { Intervention group } \\
(\mathbf{n}=85)\end{array}$} & \multirow[t]{2}{*}{$\begin{array}{l}\text { chi square } \\
\text { p- value }\end{array}$} \\
\hline & (No.) & $\%$ & (No.) & $\%$ & \\
\hline \multicolumn{6}{|c|}{ Oozing (immediate) } \\
\hline No Oozing & 35 & 41.2 & 40 & 47.1 & 1.199 \\
\hline Small Oozing & 43 & 50.6 & 41 & 48.2 & $0.549^{\text {n.s }}$ \\
\hline Medium Oozing & 7 & 8.2 & 4 & 4.7 & \\
\hline Large Oozing & 0 & 0.0 & 0 & 0.0 & \\
\hline \multicolumn{6}{|l|}{ Oozing (after 6 hours) } \\
\hline No Oozing & 18 & 21.2 & 37 & 43.5 & 9.843 \\
\hline Small Oozing & 60 & 70.6 & 44 & 51.8 & $0.007 *$ \\
\hline Medium Oozing & 7 & 8.2 & 4 & 4.7 & \\
\hline Large Oozing & 0 & 0.0 & 0 & 0.0 & \\
\hline \multicolumn{6}{|l|}{ Oozing (after 12 hours) } \\
\hline No Oozing & 26 & 30.6 & 47 & 55.3 & 10.730 \\
\hline Small Oozing & 38 & 44.7 & 23 & 27.1 & $0.005^{*}$ \\
\hline Medium Oozing & 21 & 24.7 & 15 & 16.6 & \\
\hline Large Oozing & 0 & 0.0 & 0 & 0.0 & \\
\hline
\end{tabular}

(n.s) Not Significant $(*)$ Statistically Significant at $\leq 0.05$

\section{Discussion}

Nurses play an important role in delivering care after cardiac catheterization as well as who need to engage in safe protocol in order to prevent patients' complications and improve their health outcomes, for this reason the competence of nurses about knowledge and practice regarding patient care after cardiac catheterization is very crucial. So, the current study is effort to investigate the effect of designed teaching protocol regarding patients' safety after cardiac catheterization on nurses' performance and patients' incidence of vascular complications.

Demographic Characteristics of nurses regarding age and experience distribution revealed that about half (52\%) of nurses were aged 20-39 years and (82\%) of them were female, indicating that two fifths (40\%) of the nurses were have experience in cardiac catheterization unit for less than 1 year. The advantages of nurses in young age are 
full of energy and hyperactivity which is always required in such crucial departments, as discussed in previous study of (Al-Ftlawy, 2014). According to marital status distribution it was not beneficial for institution that (76\%) of the nurses were married and (24\%) were unmarried. According to their qualification $(52 \%)$ of the nurses had General Nursing Diploma, and (48\%) of them had BSN. Besides, most of them were not taking in service educational program, this indicating that, most of nurses working in cardiac catheterization unit were in need for more in service educational programs.

Regarding nurses' knowledge about vascular complications and how to prevent its occurrence, It was revealed that, there was a significant differences between nurse's knowledge during pre and post program implementation, indicating $(86 \%)$ of them had unsatisfactory level of knowledge preprogram \& near the majority of them $(82 \%)$ reached at a satisfactory level during post program, which supporting research hypothesis (1) . This could be connected to the fact that the majority of nurses hold diploma nursing with alittle years of experience of less than one year. This study results were in the same line with (Thapa and Neupane, 2018) who conducted a study to assess the impact of teaching program on nurses knowledge concerning intra-aortic balloon pump (IABP) implantation therapy for coronary artery bypass grafting patients at selected hospitals in Dehradum and found that the majority of the studied nurses had reported adequate level of knowledge regarding IABP which increased after intervention. Additionally, Elsay et al. (2016); Mahgoub and Abd El-Hafez (2017); and Shini et al. (2018), who documented that there was significant difference between preprogram and post program knowledge with a fact of an increased level after implementing their programs than before.

Concerning nurses' practice the current study displayed that, there was a significant differences between nurse's practice during pre and post program implementation, indicating (100\%) of them had inadequate level of practice preprogram \& $(58 \%)$ of them had adequate level during post program implementation, this may be due to the readiness of nursing staff to improve their practice and accept any recent guidelines regarding their performance especially those of young age where about half of nursing staff aged less than 30 years, which supporting research hypothesis (2) and approving the effectiveness of the teaching protocol in improving nurses' practice. This result comes in agreement with Thomas (2013) who implemented study to evaluate the effect of video assisted program teaching on staff nurses practice and knowledge regarding defibrillation and cardio version as a cardiac unit in Bagalkot hospitals and illustrated that there were statistically significant difference between post and pretest practice scores.

The current study also showed that there was positive and significant correlation between nurse's knowledge and practice during post program implementation, which supporting research hypothesis (3) pointing out that, high level of nurses' knowledge reflected on their practice; knowledgeable nurses provide more accurate care. This result is in the same line with Feroze et al. (2017) who found a positive correlation between the skills and knowledge regarding patent's safety following cardiac catheterization in Pakistanis where, registered nurses and nurses that have adequate skills and knowledge which reflected on improved patient safety.

\section{Referring to Demographic Characteristics of patients:}

The present study presented that, there were no significant statistical differences between both intervention and control groups concerning characteristics, revealing the homogeneity among study subjects regarding their characteristics, where the majority of both groups were in age group 50 to less than 60 years old, with a mean age of (54.60 $\pm 4.78 \& 54.31 \pm 4.94$, respectively) among control and intervention groups. This in line with Hassan et al. (2015), whose study was performed to evaluate the feasibility and safety of early sheath removal after percutaneous coronary intervention (PCI) using a locally designed Assiut Femoral Compression Device (AFCD2) vs. manual compression (MC), and found that (37\% \& $38 \%$, respectively) of the study sample were males, and their mean age was of ( $57 \pm 9 \& 56 \pm 10$, respectively) years old. This may be related to changes of the heart and blood vessels that occur with aging such as the decrease in elasticity and the ability to respond to changes in compliance of the arterial system that increase the work needed to drive the blood to various organs of the body due to resultant increase in the resistance to the pumping action of the heart. Besides, most patients were males. This can be attributed to the higher exposure to life stress and smoking. Moreover, female hormones protects female from coronary artery disease (CAD), which agreed with Elsaid et al (2015) who studied the Effect of Early Ambulation; Three versus Five hours after Transfemoral diagnostic Cardiac Catheterization and reported that, more than half of their studied patients were males. While it contradicted with Galiuto (2015) who revealed that, cardiac catheterization procedure due to coronary vascular disease (CVD) occurs similarly in men and women especially after menapause, because estrogen deficiency leads to several structural and functional changes in cardiovascular system which increase of cardiovascular risk. 
Also the current study revealed that, the majority of the studied patients were married. This is in line with Mohammed et al. (2016), who conducted study about the Impact of Designed Nursing Educational Protocol on Health Promotion for Patients Undergoing Coronary Artery Stent Outcome, which revealed that the majority of the studied sample was married. This may be attributed to the high level of daily life stress and social responsibilities among married patients than single one and that stress is considered one of the most aggravating factors for CAD. Moreover it was displayed in the current study that, body mass index was $\{28.83 \pm 1.46 \& 29.10$ \pm 1.00 , respectively $\}$ among control and intervention groups reflecting one of predisposing factors which led to CAD as being overweight or obese, similar to (Sulzbach-Hoke et al., 2010) who revealed in their study that BMI of studied subjects was around $29 \mathrm{~kg} / \mathrm{m}^{2}$

Regarding pateints' clinical data, the current study reported that there was no significant differences between both (control \& intervention groups), indicating that both groups had comorbid diseases (hypertension \& diabetes). This is because hypertension \& diabetes considered one of the risk factors for all types of cardiac diseases and hematoma incidence, which stand in line with (Tewari et al., 2013) who reported that, patients undergoing transfemoral diagnostic cardiac catheterization have history of hypertenstion (HTN), and diabetes mellitus (DM). As well as (63.5\% \& $49.4 \%$, respectively) of both groups were used femoral sheath size 7 FR, this is because the fact that, the strongest preventable risk factor for hematoma formation was sheath size, while simultaneously reducing the sheath size too much would probably reduce the chances of angiographic success, this result is in line with Mohammed e al. (2013) who had similary mentioned that A7, 8FR sheaths were mostly used among patients undergoing percutaneous coronary procedures.

As regard to the use of heparin pre and during the procedure, the present study results had shown that the majority of patients on both groups had no significant statistically differences. These findings are in agreements with Mohammed et al. (2013) who reported that during the Percutaneous Transluminal Coronary Angioplasty (PCTA) procedure, patients receive intravenous heparin for some time-after the procedure to prevent clot formation and arterial spasm. Also, nurses need to be vigilant when caring for patients who have had vascular complications prior to femoral sheath removal and had received antiplatelet medications.

Concerning hematoma formation as a vascular complication among patients in both control and intervention groups, the current study had revealed that there was no significant difference between both groups regarding incidence of hematoma immediately after sheath removal, while there was a significant difference after (6 hrs and $12 \mathrm{hrs)} \mathrm{of} \mathrm{removal} \mathrm{reflecting} \mathrm{the} \mathrm{higher} \mathrm{percent} \mathrm{of} \mathrm{intervention} \mathrm{group} \mathrm{during} \mathrm{these} \mathrm{period} \mathrm{had} \mathrm{no}$ hematoma, which supporting research hypothesis (4). It may be attributed to that, development of complications in cardiac patients after cardiac catheterization is minimal due to good knowledge of nurses about post cardiac complication and satisfactory practice. It is congruent with results of the study carried out by Benson et al. (2009), where patients who underwent sheath removal using the compressor or bandage pressure had a decreased level of hematoma at the end of assessment period, also Rezaei-Adaryani et al. (2009) who assessed the effect of changing position and early ambulation on the amount of bleeding and hematoma after cardiac catheterization, and concluded that the experimental group produced no significant increase in the amount of bleeding and hematoma when compared with the control group ( $\mathrm{P}>0.05$ ). On the same vein, Hamel (2012) revealed that hematoma increased immediately after sheath removal, and decreased at 12-hour from assessment period among the study group. Also Larson et al. (2014), added in their study about immediate mobilization after coronary angiography or percutaneous coronary intervention following hemostasis with angioseal vascular closure device that, no major bleeding complications were seen between the groups with baseline characteristics did not differ between the groups, as well as Schupke et al. (2014), declared in their study that, the incidence of hematoma was lower in patients assigned to the intervention group compared with those in control group

As regards, incidence of ecchymosis as a vascular complication among patients in both control and intervention groups, the present study has revealed that there was no significant difference between both groups regarding incidence of ecchymosis immediately after sheath removal, while there was a significant difference after (6 hrs and $12 \mathrm{hrs)}$ of removal, which supporting research hypothesis (4) and reflecting the higher percent of intervention group during these periods had no ecchymosis. This finding comes in agreement with Mohammed et al. (2013) who reported that, there was no significant difference between the studied groups regarding incidence of vascular complications immediately after sheath removal, while there was a significant difference after (6hrs and $12 \mathrm{hrs}$ ) of removal in term of lower incidence among intervention (bandage and compression device) groups. Also Vati et al. (2016) added in their study about the Effect of Low Fowler's Position on Back Pain and Vascular Complications following Trans-Femoral Cardiac Catheterization that the control group patients (on supine position) significantly developed ecchymosis as compared to the experimental group (on low fowler position) $(p<0.02)$ at the time of removal of dressing from the puncture site at 12 hours after catheterization. 
For the incidence of oozing as a vascular complication among patients in both control and intervention groups, the present study reported that, there was no significant difference between both groups regarding incidence of oozing immediately after sheath removal, while there was a significant difference after (6hrs and 12hrs) of removal, which supporting research hypothesis (4), and reflecting that the higher percent of intervention group had small oozing after $6 \mathrm{hrs}$ and higher percent of them had no oozing after12hrs of sheath removal. These findings are in agreement with Mohammady et al. (2014) who had reported that their intervention was associated with increasing comfort and satisfaction levels without increasing the amount of bleeding or (oozing) after sheath removal among intervention group. Conversely, these present study results are contradicted with that of Jones (2012) who had reported that bleeding from the femoral puncture site after femoral sheath removal did not differ scientifically in either study or control group

\section{Conclusion}

The designed teaching protocol was effective in improving nurses' knowledge and practice, which were positively associated with each other and lower the incidence of vascular complications among patients in the intervention group.

\section{Recommendations}

\section{Based on the results of the study, the following recommendations are suggested:}

1- Equipping cardiac catheterization unit with simple illustrated guidelines protocol covering PCI procedure practices knowledge pre/post cardiac catheterization.

2- Developing an in service audiovisual materials training/education about cardiac catheterization, types, indications, complications \& instructions before, during and after procedure for patients.

3- Reapply this research on a larger probability sample acquired from different geographical areas in Egypt for generalization.

\section{Acknowledgement}

We would like to extend our deep thanks to all health personnel in the cardiac catheterization unit of Benha university Hospital as well as the patients involved in the study for their cooperation in the fulfillment of this study.

\section{References}

Ahmed, A.I. (2015). Predictors of Post-Cardiac Catheterization Femoral Artery Hematoma and Bleeding. Journal of American Science, 11(3), 16-22. Retrieved from http://www.jofamericanscience.org

Al Sadi, A., Yousef, A., \& Al-Zarui, M. (2010). Timing and Predictors of Femoral Hematoma Development after Manual Compression of Femoral Access Sites. J. Pak Med Assoc, 60(8), 620-625.

Al-Ftlawy, D. (2014). Determination of Nurses' Knowledge Toward Care Provided to Patients with Acute Myocardial Infarction in Al-Najaf City. Kufa Journal for Nursing Sciences, 2(2).

Arathy, S.R. (2011). A study to Assess the Knowledge and Practices among Cardiac Nurses about Patient Safety after Cardiac Catheterization, Submitted in the partial fulfillment of the requirements for the Diploma in Cardiovascular and Thoracic nursing, Sree Chitra Tirunal Institute for Medical Science and Technology Triv Andrum, 695011.

Benson, L., Wunderly, D., Perry, B., Wenk, T., \& Birdsall, B. (2009). Determining Best Practice: Comparison of Three Methods of Femoral Sheath Removal after Cardiac Interventional Procedures. Heart Lung, 34(2), 115-21. https://doi.org/10.1016/j.hrtlng.2004.06.011

Black, J.M. (2008). Medical Surgical Nursing (7th ed.). WB Saunders, P. 1627.

Chen, T., \& Crozier, J. (2014). Endovascular Repair of Thoracic Aortic Pathologies: Postoperative Nursing Implications. Journal of Vascular Nursing, 32(2), 63-69. https://doi.org/10.1016/j.jvn.2013.07.001

Ebeed, M.E., Khalil, N.S., \& Ismaeel, M.S. (2017). Vascular Complications and Risk Factors among Patients Undergoing Cardiac Catheterization. Egypt Nurs J, 14, 259-68. https://doi.org/10.4103/2090-6021.233668

Elsaid, R., Soliman, H., Sobh, H., \& Maaty, A. (2015). Effect of Early Ambulation; Three versus Five hours after Transfemoral diagnostic Cardiac Catheterization: A randomized clinical One-arm Study. Journal of Nursing and Health Science, 4(5), 12-20.

Elsay, O., Elshemy, M., \& Elsays, H. (2016). Effect of Multi-Modal Preparation Package on Knowledge and Anxiety among Patients Undergoing Cardiac Catheterization. International Cardiovascular Research 
Journal, 5(5), 222-31.

Feroze, M., Afzal, M., Sarwar, H., Galani, A., \& Afshan, S. (2017). Assess Knowledge and Practice of Registered Nurses about Patient Safety after Cardiac Catheterization in Punjab Institute of Cardiology Hospital, Lahore. International Journal of Musculoskeletal Pain prevention, 2(2).

Galiuto, L. (2015). Gender differences in cardiovascular disease. Retrieved February 8, 2018, from https://www.oatext.com/Gender-differences-in-cardiovascular-disease.php

Hamel W.J. (2012). Femoral Artery Closure after Cardiac Catheterization. American Association of Critical -Care Nurses, 29(1), 39-46.

Hamner, J.B., Dubois, E.J., \& Rice, T.P. (2010). Predictors of Complications Associated with Closure Devices after Transfemoral Percutaneous Coronary Procedures. Critical Care Nursing, 25, 30-7.

Hassan, A., Ali, H., Demetry, S., Refaat, R., \& Ali, A. (2015). Early Sheath Removal after Percutaneous Coronary Intervention Using Assiut Femoral Compression Device is Feasible and Safe. Results of A randomized Controlled Trial. The Egyptian Heart Journal, 67, 69-77. https://doi.org/10.1016/j.ehj.2014.10.003

Jones, T. (2012). Effectiveness of Mechanical Compression Devices in Attaining Hemostasis after Femoral Sheath Removal. Coronary Intervention Crit Care Nurse, 32, 16-29.

Larson, E., Hansen, C., Thayssen, P., \& Jensen, L. (2014). Immediate Mobilization after Coronary Angiography or Percutaneous Coronary Intervention Following Hemostasis with Angioseal Vascular Closure Device (The MOBS Study). Block-Randomized, Quantitative Study. European Journal of Cardiovascular Nursing, 13(5), 466-72. https://doi.org/10.1177/1474515113516702

Mahgoub, A.A., \& Abd El-Hafez, A.I. (2017). Effect of implementing intra-orticballon pump teaching program on critical care nurse's knowledge and practice. IOSR Journal of Nursing and Health Science, 6(1), 54-62.

Mohammady, M., Heidari, K., Sari, A., Zolfaghari, M., \& Janani, L. (2014). Early Ambulation after Diagnostic Transfemoral Catheterisation: A systematic review and meta-analysis. International Journal of Nursing Studies, 51, 39-50. https://doi.org/10.1016/j.ijnurstu.2012.12.018

Mohammed, G., Mohammed, Z., \& Al-Araby, H. (2016). Impact Of Designed Nursing Educational Protocol On Health Promotion For Patients Undergoing Coronary Artery Stent Outcome. IOSR Journal of Nursing and Health Science (IOSR-JNHS), 5(2), 54-63.

Mohammed, H., Said, H., \& Salah, M. (2013). Determining Best Nursing Practice: Effectiveness of Three Groin Compression Methods Following Cardiac Catheterization. J Am Sci, 9(6), 274-285. Retrieved from http://www.jofamericanscience.org

Panesar, S., De Silva, D., Carson-Stevens, A., Cresswell, K., Salvilla, S., Slight, S., ... Sheikh, A. (2016). How Safe Is Primary Care? A systematic Review. BMJ Qual Saf, 25, 544-553. https://doi.org/10.1136/bmjqs-2015-004178

Panizza, P., Viana, P., Marcelino, A., Costa, F., Vendramini, D., Azambuja, R., \& Paulo, S. (2017). Femoral vascular access-site complications: The role of radiology in diagnosis and management. European Society of Radiology.

Parkinson, J. (2015). An Evaluation of Peripheral Vascular Access Site Complications Following Coronary Angiography and Percutaneous Coronary Intervention. Published Master Thesis. Sydney Nursing School.University of Sydney.

Rezaei-Adaryani, M., Ahmadi, F., \& Asghari-Jafarabadi, M. (2009). The Effect of Changing Position and Early Ambulation after Cardiac Catheterization on Patients' Outcomes: A single-Blind Randomized Controlled Trial. Int J Nurs Stud, 46(8), 1047-53. https://doi.org/10.1016/j.ijnurstu.2009.02.004

Santos, A., \& Ward, K. (2017). Care of the Patient Post Cardiac Catheterization. Retrieved December 25, 2018, from

https://www.rch.org.au/rchcpg/hospital_clinical_guideline_index/Care_of_the_patient_post_cardiac_cathete risation/

Schupke, S., Helde, S., Gewalt, S., Ibrahim, T., Linhardt, M., Haas, K., \& Kastrati, A. (2014). Comparison of Vascular Closure Devices. Manual Compression after Femoral Artery Puncture: The ISAR-Closure Randomized Clinical Trial; Randomized, large-scale, multicenter, Open-Label Clinical Trial. The Journal of the American Medical Association, 312(19), 1981-7. https://doi.org/10.1001/jama.2014.15305 
Shini, S., Laly, P., \& Smitha, P. (2018). Effectiveness of Nursing Care Protocol on Knowledge and Performance among Staff Nurses Regarding Management of Patients Undergoing Coronary Angioplasty GJRA. Journal for Research Analysis, 7(1), 4-5.

Sulzbach-Hoke, L.M., Ratcliffe, S.J., Kimmel, S.E., Kolansky, D.M., \& Polomano, R. (2010). Predictors of Complications Following Sheath Removal with Percutaneous Coronary Intervention. Journal of Cardiovascular Nursing, 25(3).

Tewari, S., Sharma, N., Kapoor, A., Syal, S., Kumar, S., Garg, N., \& Goeld, P. (2013). Comparison of Transradial and Transfemoral Artery Approach for Percutaneous Coronary Angiography and Angioplasty: A Retrospective Seven-Year Experience from A north Indian Center. Indian Heart Journal, 65(4), 378-87. https://doi.org/10.1016/j.ihj.2013.06.020

Thapa, R., \& Neupane, G. (2018). Intra-Aortic Ballon Pump Implantation Therapy. International Journal of Recent Scientific Research, 9(2), 24459-62.

Thomas, M. (2013). A study to Evaluate the Effectiveness of Video Assisted Teaching Program on Knowledge and Practice Regarding Cardioversion and Defibrillation Among Staff Nurses Working in Cardiac Unit in Selected Hospitals of Bagalkot. Master thesis. Rajiv Gandhi university of Health Science, Karnataka, India.

Vati, J., Mathew, T., \& Sharma, Y. (2016). Effect of Low Fowler's Position on Back Pain and Vascular Complications Following Trans-Femoral Cardiac Catheterization: A Randomized Controlled Trial. I-Manager's Journal on Nursing, 6(1), 24-31. https://doi.org/10.26634/jnur.6.1.5916

Yamane, T. (1967). Statistics an Introductory Analysis (2nd ed.). New York Harper and Row CO. USA, p. 213.

\section{Copyrights}

Copyright for this article is retained by the author(s), with first publication rights granted to the journal.

This is an open-access article distributed under the terms and conditions of the Creative Commons Attribution license (http://creativecommons.org/licenses/by/4.0/). 